\title{
Higher Responsiveness to Rosuvastatin in Polygenic versus Monogenic Hypercholesterolemia: A Propensity Score Analysis
}

\author{
Agnieszka Mickiewicz ${ }^{1, *(\mathbb{D},}$, Marta Futema ${ }^{2}$, Agnieszka Ćwiklinska $^{3}$, Agnieszka Kuchta $\left.^{3}{ }^{(}\right)$, \\ Maciej Jankowski ${ }^{3}$ D, Mariusz Kaszubowski ${ }^{4}$, Magdalena Chmara ${ }^{5}$, Bartosz Wasąg ${ }^{5}$ (D), \\ Marcin Fijałkowski ${ }^{1}$, Miłosz Jaguszewski ${ }^{1}$, Steve E. Humphries ${ }^{6}$ and Marcin Gruchała ${ }^{1}$ \\ 1 Department of Cardiology I, Medical University of Gdansk, Dębinki 7, 80-211 Gdańsk, Poland; \\ marcin.fijalkowski@gumed.edu.pl (M.F.); milosz.jaguszewski@gumed.edu.pl (M.J.); \\ marcin.gruchala@gumed.edu.pl (M.G.) \\ 2 Centre for Heart Muscle Disease, Institute of Cardiovascular Science, University College London, \\ London WC1E 6BT, UK; marta.futema.10@ucl.ac.uk \\ 3 Department of Clinical Chemistry, Medical University of Gdansk, Dębinki 7, 80-211 Gdańsk, Poland; \\ agnieszka.cwiklinska@gumed.edu.pl (A.Ć.); agnieszka.kuchta@gumed.edu.pl (A.K.); \\ maciej.jankowski@gumed.edu.pl (M.J.) \\ 4 Institute of Statistics, Department of Economic Sciences, Faculty of Management and Economics, Gdansk \\ University of Technology, 80-233 Gdańsk, Poland; mkaszubo@zie.pg.gda.pl \\ 5 Department of Biology and Genetics, Medical University of Gdansk, Dębinki 1, 80-211 Gdańsk, Poland; \\ mchmara@gumed.edu.pl (M.C.); bwasag@gumed.edu.pl (B.W.) \\ 6 Centre for Cardiovascular Genetics, British Heart Foundation Laboratories, Institute of Cardiovascular \\ Science, the Rayne Building University College London, London WC1E 6JF, UK; steve.humphries@ucl.ac.uk \\ * Correspondence: amickiewicz@gumed.edu.pl; Tel.: +48-58-349-25-00; Fax: +48-58-346-12-01
}

Received: 22 April 2020; Accepted: 16 May 2020; Published: 20 May 2020

check for updates

\begin{abstract}
Background: The monogenic defect in familial hypercholesterolemia (FH) is detected in $\sim 40 \%$ of cases. The majority of mutation-negative patients have a polygenic cause of high LDL-cholesterol (LDL-C). We sought to investigate whether the underlying monogenic or polygenic defect is associated with the response to rosuvastatin. Methods: FH Individuals were tested for mutations in $L D L R$ and $A P O B$ genes. A previously established LDL-C-specific polygenic risk score (PRS) was used to examine the possibility of polygenic hypercholesterolemia in mutation-negative patients. All of the patients received rosuvastatin and they were followed for $8 \pm 2$ months. A propensity score analysis was performed to evaluate the variables associated with the response to treatment. Results: Monogenic subjects had higher mean $( \pm \mathrm{SD})$ baseline LDL-C when compared to polygenic $(7.6 \pm 1.5 \mathrm{mmol} / \mathrm{L}$ vs. $6.2 \pm 1.2 \mathrm{mmol} / \mathrm{L} ; p<0.001)$. Adjusted model showed a lower percentage of change in LDL-C after rosuvastatin treatment in monogenic patients vs. polygenic subjects $(45.9 \%$ vs. $55.4 \%, p<0.001)$. The probability of achieving LDL-C targets in monogenic FH was lower than in polygenic subjects $(0.075$ vs. $0.245, p=0.004)$. Polygenic patients were more likely to achieve LDL-C goals, as compared to those monogenic (OR 3.28; 95\% CI: 1.23-8.72). Conclusion: Our findings indicate an essentially higher responsiveness to rosuvastatin in $\mathrm{FH}$ patients with a polygenic cause, as compared to those carrying monogenic mutations.
\end{abstract}

Keywords: polygenic hypercholesterolemia; monogenic hypercholesterolemia; rosuvastatin; propensity score 


\section{Introduction}

Familial Hypercholesterolemia (FH) is an inherited lipid disorder affecting roughly one in 250 individuals [1,2]. Long life elevated low density lipoprotein cholesterol (LDL-C) concentrations translate into advanced cardiovascular disease (CVD) [3-5]. Clinical criteria are useful for diagnosing $\mathrm{FH}$ and selecting patients for genetic testing of three genes coding for proteins that are involved in the clearance of LDL-C from blood: LDL-receptor ( $L D L R)$, apolipoprotein B $(A P O B)$, and pro-protein convertase subtilisin kexin 9 (PCSK9) [2,6-8]. Nevertheless, the mutations in those three genes can only be detected in $\sim 40 \%$ of patients with a clinical diagnosis of FH [4]. It has been previously estimated that a substantial proportion of individuals with clinical phenotype of $\mathrm{FH}$ and negative result of $\mathrm{FH}$ mutational analysis presents elevated LDL-C concentrations due to a polygenic cause [9]. Those patients inherit a higher than average number of common genetic variants with LDL-C-rising effect and can be identified based on polygenic risk score (PRS) constructed from the top six single nucleotide polymorphisms (SNPs) located in LDLR, APOB, APOE, ABCG8, and SORT1 [10].

Nevertheless, the clinical importance of diagnosing monogenic and polygenic hypercholesterolemia for $\mathrm{CV}$ risk assessment and adjusting the intensity of lipid lowering treatment (LLT) remain uncertain [11-14]. Sharifi et al. showed that the carotid intima media thickness (IMT) and coronary artery calcium (CAC) score, as an indicators of the development of subclinical atherosclerosis, are greater in asymptomatic monogenic FH when comparing to age- and gendermatched asymptomatic polygenic hypercholesterolemia cases [15].

The response to statin therapy has been reported to be related to the genetic basis of FH. In one of the studies, the response to atorvastatin, measured as a mean percentage LDL-C reduction, was significantly higher in heterozygous $\mathrm{FH}(\mathrm{HeFH})$ caused by the class 5 mutation in $L D L R$ as compared to $\mathrm{HeFH}$ individuals with class 2 mutations [16].

Importantly, there is a lack of a comparison of the rosuvastatin efficacy in patients with monogenic vs. polygenic hypercholesterolemia. Thus, the aim of our study was to evaluate the responsiveness to rosuvastatin in patients that were classified as monogenic $\mathrm{FH}$ and polygenic hypercholesterolemia. We applied comparative effectiveness analyses while using Inverse Probability Weighted Regression Adjustment (IPWRA) models in order to minimize the possible bias of non-random assignment of the rosuvastatin treatment.

\section{Materials and Methods}

Individuals $(\mathrm{n}=112)$ from outpatient lipid clinic in First Department of Cardiology, Gdansk, Poland, with clinical diagnosis of FH according to validated criteria, were included into the study [17]. The exclusion criteria comprised secondary causes of hypercholesterolemia such as diabetes, hypothyreosis, chronic kidney disease, cholestasis, corticosteroids use as well as the triglyceride (TG) concentration $>4,1 \mathrm{mmol} / \mathrm{L}$.

All of the patients receiving lipid lowering therapy (LLT) were followed for at least six months (mean $8 \pm 2$ ) and assessed at least twice during this period. The time points of LDL-C measurements (calculated from Friedewald formula) were defined, as follows: at baseline and before the initiation of rosuvastatin treatment, and after at least six months of LLT.

The patients were enrolled prospectively based on protocol prepared ad hoc. The study was reviewed and accepted by the local Ethics Committee (Ethic Codes NKBBN/492/2011-2012 and 362/2019). The informed consent for participation in the study was obtained from all participants. The study complies with the Declaration of Helsinki.

\subsection{Molecular Testing}

Genomic DNA was isolated from whole blood while using standard methods [18] and mutational analysis of $L D L R$ and $A P O B$ was performed in all individuals [19]. A fragment of exon 26 of the $A P O B$ gene located between codons 3473-3606, which covers the region of the most frequent FH mutation, 
was screened by using Sanger sequencing [20]. LDLR variants were classified into five categories, as indicated by the Association for Clinical Genomic Science, and only individuals with variants that were categorized as class 4 and 5 were diagnosed as monogenic hypercholesterolemia [21].

Mutation-negative patients were genotyped for six LDL-C-raising single nucleotide polymorphisms (SNPs) located in: CELSR2 (rs629301), APOB (rs1367117), ABCG8 (rs4299376), LDLR (rs6511720), and APOE (rs429358, and rs7412) at the Cardiovascular Genetics Lab at UCL in the UK with the previously described methods $[9,10]$. A previously validated LDL-C gene score was calculated for each patient $[9,10,22]$. Since no control cohort representing the general population is currently available for the PRS analysis, we used quartile cut-offs of the PRS distribution data for the British cohort of Caucasians, the Whitehall II study [9]. The investigated subjects were divided into quartiles of their PRS based on the Whitehall II population. Those with no detectable mutation in LDLR/APOB and SNPs in the top 2 quartiles (PRS > 0.65) were defined as polygenic hypercholesterolemia.

\subsection{Lipid Lowering Therapy}

Rosuvastatin was administrated and adjusted in the dose according to the individual decision of physician and patients' tolerance, aiming to achieve the LDL-C targets based on clinical diagnosis of FH and LDL-C concentrations. The use of ezetimibe was based on the individual decision of the physician. LLT was administrated without any knowledge of the result of genetic testing.

Demographic data, medical history, and parameters associated with LLT, including statin associated muscle symptoms, were evaluated.

High intensity therapy was defined as daily administration of $20-40 \mathrm{mg}$ of rosuvastatin.

We have collected the information about the drug intake by using specially prepared case report form (CRF) to assess the adherence to LLT use.

We assessed previously applied LDL-C goals defined per European Society of Cardiology guidelines [23].

\subsection{Statistical Analysis}

Descriptive statistical evaluations were expressed as numbers and percentages for categorical variables, and as mean with standard deviation (SD) or median with interquartile range (IQR) for continuous variables, when appropriate. The difference between the groups with regards to categorical variables was determined by the Pearson $\chi^{2}$ or Fisher exact tests. For continuous variables, the difference between two independent groups was determined by the Welch's t-test or U Mann-Whitney test, if necessary.

Models have been constructed for two dependent variables to examine the influence of an underlying genetic defect in $\mathrm{FH}$, monogenic or polygenic, on LLT efficacy: percentage of LDL-C reduction (continuous) and LDL-C goal (binomial). The type of hypercholesterolemia (polygenic or monogenic), as well as following variables: age, gender, LDL-baseline, statin intolerance, ezetimibe use, rosuvastatin dose, diabetes, and cardiovascular disease, were examined. The LDL-C goal achievement included reaching both LDL-C targets: in secondary prevention LDL-C $<1.8 \mathrm{mmol} / \mathrm{L}$ and in primary prevention LDL-C $<2.5 \mathrm{mmol} / \mathrm{L}$.

The LDL-C reduction variable represented the percentage change of LDL-C after treatment and it was calculated as:

$$
L D L-C \text { reduction }=\frac{L D L-C \text { baseline }-L D L-C \text { after treatment }}{L D L-C \text { baseline }} \times 100 \%
$$

Methods that were conducted for the analysis of LDL-C reduction included: Multiple Linear Regression, ANCOVA (covariance analysis) and Inverse Probability Weighted Regression Adjustment (IPWRA) based on Propensity Score Analysis. 
Stepwise analysis with bidirectional elimination method was used to build a multivariate linear regression model. All of the clinically relevant assumptions were tested, namely: normality of residuals (W Shapiro-Wilk test), heteroscedasticity (Breusch-Pagan/Cook-Weisberg test), and multicollinearity (variance inflation factors). Identical set of dependent variables as in regression model was used in covariance analysis (ANCOVA) to calculate the expected marginal means of LDL-C reduction concentration with average values of covariates. An assumption of parallelism was also tested.

The model of discussed relations was based on Potential-outcome models and Propensity Score Analysis (Inverse Probability Weighted Regression Adjustment) to precisely account for non-random assignment to rosuvastatin treatment [24]. A Propensity Score Analysis was implemented while using a multivariable logistic regression model with the use of previous set of variables (the type of hypercholesterolemia-polygenic or monogenic, age, gender, LDL-baseline, statin intolerance, ezetimibe use, rosuvastatin dose, diabetes, and cardiovascular disease) to predict probabilities of conditional treatment assignment on covariates at baseline. Most important for IPWRA, overlap assumption, was verified by density graph of the predicted probabilities (Epanechnikov kernel function). The calculated potential-outcome means (POMeans) as well as frame charts of means with standard errors were presented.

Logistic regression and IPWRA analyses were performed to analyse the achievement of LDL-C goals. The final logistic model was statistically significant as well as each of its independent variables. Additionally, Pearson and Hosmer-Lemeshow goodness of fit test was performed. Outcome model and treatment model were established similarly as the models for LDL-C reduction (\%), except the fact that outcome model was logit, not linear. The potential-outcome means (as probabilities of achieving a goal) were calculated.

The level of significance was set at $p=0.05$. All of the statistical analyses were performed by using Statistica v13.1 (Dell Inc., Round Rock, TX, USA 2016, data analysis software system) and STATA 13 (StataCorp LP, College Station, TX, USA).

\section{Results}

\subsection{Molecular Testing}

Out of the 112 clinical FH subjects, 47 individuals were found to carry an FH-causing variant: $40(85 \%)$ carried a mutation in $L D L R$, and seven $(15 \%)$ in $A P O B$ (all APOB-mutations were the p.R3527Q). All of the FH-causing variants identified in this study are shown in Supplementary Table S1. The remaining 65 mutation-negative FH patients were genotyped for six LDL-C-associated SNPs. All the mutation-negative patients had a weighted LDL-C PRS above the second quartile of the score distribution, based on the Whitehall II population. These individuals were defined as having a high probability of polygenic cause of hypercholesterolemia. When compared to the Whitehall II population $(\mathrm{n}=3020)$, the PRS in the mutation-negative FH group was significantly higher $(0.632 \pm 0.22$ vs. 0.818 $\pm 0.09 ; p<0.001)$.

\subsection{Patients' Clinical Characteristics and Lipid Lowering Therapy Data}

The clinical characteristics and comparison of LLT data for monogenic vs. polygenic hypercholesterolemic subjects are shown in Tables 1 and 2, respectively. The age and gender distributions were comparable in both groups. The individuals positive for $L D L R / A P O B$ mutations were more often diagnosed with definite $\mathrm{FH}$ when compared to the mutation negative patients. 
Table 1. Characteristics of individuals with monogenic hypercholesterolemia and polygenic hypercholesterolemia.

\begin{tabular}{|c|c|c|c|}
\hline Parameter & $\begin{array}{c}\text { Polygenic } \\
\text { Hypercholesterolemia } \\
\mathrm{n}=65\end{array}$ & $\begin{array}{c}\text { Monogenic } \\
\text { Hypercholesterolemia } \\
\mathrm{n}=47\end{array}$ & $p$ Value \\
\hline Age, years * & $54.37 \pm 12.54$ & $50.57 \pm 13.49$ & 0.134 \\
\hline Female & $42(64.62 \%)$ & $28(59.57 \%)$ & 0.586 \\
\hline Prevention Primary & $48(73.85 \%)$ & $31(65.96 \%)$ & 0.366 \\
\hline Prevention Secondary & $17(26.15 \%)$ & $16(34.04 \%)$ & 0.366 \\
\hline CVD & $15(23.08 \%)$ & $15(31.91 \%)$ & 0.297 \\
\hline CAD & $13(20.00 \%)$ & $13(27.66 \%)$ & 0.343 \\
\hline CAD age, years * & $49.45 \pm 10.96$ & $47.30 \pm 3.56$ & 0.548 \\
\hline MI & $21(32.31 \%)$ & $8(17.02 \%)$ & 0.311 \\
\hline MI age, years * & $48.70 \pm 11.25$ & $47.38 \pm 5.40$ & 0.748 \\
\hline PCI & $7(10.77 \%)$ & $9(19.15 \%)$ & 0.211 \\
\hline PCI age, years * & $46.57 \pm 12.16$ & $46.78 \pm 3.35$ & 0.966 \\
\hline CABG & $4(6.15 \%)$ & $3(6.38 \%)$ & 0.961 \\
\hline CABG age, years * & $48.00 \pm 5.20$ & $51.5 \pm 0.71$ & 0.364 \\
\hline Stroke/TIA & $3(4.62 \%)$ & $2(4.26 \%)$ & 0.748 \\
\hline Smoking & $11(16.92 \%)$ & $7(14.89 \%)$ & 0.783 \\
\hline HA & $22(33.85 \%)$ & $23(48.94 \%)$ & 0.169 \\
\hline $\mathrm{DM}$ & $6(9.23 \%)$ & $2(4.26 \%)$ & 0.303 \\
\hline BMI $\left(\mathrm{kg} / \mathrm{m}^{2}\right)^{*}$ & $26.57 \pm 4.11$ & $26.24 \pm 4.62$ & 0.720 \\
\hline $\begin{array}{l}\text { FH } \\
\text { Definite } \\
\text { Probable } \\
\text { Possible }\end{array}$ & $\begin{array}{c}2(3.08 \%) \\
29(44.62 \%) \\
34(52.31 \%)\end{array}$ & $\begin{array}{c}24(51.06 \%) \\
21(44.68 \%) \\
2(4.26 \%)\end{array}$ & $\begin{array}{c}<0.001 \\
0.995 \\
<0.001\end{array}$ \\
\hline $\begin{array}{c}\text { Family history of } \\
\text { hypercholesterolemia in adults } \\
\text { aged }>18 \text { years defined as } \\
\text { LDL-C }>4.9 \mathrm{mmol} / \mathrm{L} \\
(190 \mathrm{mg} / \mathrm{dL})\end{array}$ & $22(33.85 \%)$ & $39(82.98 \%)$ & $<0.001$ \\
\hline $\begin{array}{l}\text { Family history of } \\
\text { hypercholesterolemia in } \\
\text { children defined as LDL-C } \\
>4.0 \mathrm{mmol} / \mathrm{L}(155 \mathrm{mg} / \mathrm{dL})\end{array}$ & $6(9.23 \%)$ & $12(25.53 \%)$ & 0.021 \\
\hline $\begin{array}{l}\text { Family history of premature } \\
\text { CAD (in men below age } 55 \text {, in } \\
\text { women below } 60 \text { years) }\end{array}$ & $49(75.38 \%)$ & $35(74.47 \%)$ & 0.912 \\
\hline Corneal arcus $<45$ y & $1(1.54 \%)$ & $5(10.64 \%)$ & 0.046 \\
\hline Tendinous xanthomata & 0 & $1(2.13 \%)$ & 0.420 \\
\hline
\end{tabular}

Data are presented as * mean \pm standard deviation or as number (percentage). Abbreviations: BMI-Body mass index, CAD—coronary artery disease, CABG—Coronary artery bypass grafting, CVD—Cardiovascular disease, DM-diabetes, FH—familial hypercholesterolemia, HA-arterial hypertension, MI-myocardial infarction, PCI-percutaneous intervention, TIA—transient ischemic attack. 
Table 2. Lipid profiles, lipid-lowering therapy and the achievement of LDL-C treatment goals.

\begin{tabular}{|c|c|c|c|}
\hline Parameter & $\begin{array}{c}\text { Polygenic } \\
\text { Hypercholesterolemia } \\
\text { N }=65\end{array}$ & $\begin{array}{c}\text { Monogenic } \\
\text { Hypercholesterolemia } \\
\mathrm{N}=47\end{array}$ & $p$ Value \\
\hline \multicolumn{4}{|c|}{ Lipid profile parameters before and after treatment } \\
\hline \multicolumn{4}{|l|}{$\mathrm{TC}(\mathrm{mmol} / \mathrm{L}) *$} \\
\hline baseline & $8.6 \pm 1.2$ & $10.0 \pm 1.8$ & $<0.001$ \\
\hline after treatment & $5.0 \pm 0.9$ & $5.7 \pm 1.2$ & $<0.001$ \\
\hline \multicolumn{4}{|l|}{ LDL-C (mmol/L)* } \\
\hline baseline & $6.2 \pm 1.2$ & $7.6 \pm 1.5$ & $<0.001$ \\
\hline after treatment & $2.9 \pm 0.7$ & $3.8 \pm 1.1$ & $<0.001$ \\
\hline \multicolumn{4}{|l|}{ non HDL-C $(\mathrm{mmol} / \mathrm{L}) *$} \\
\hline baseline & $7.0 \pm 1.4$ & $8.3 \pm 1.7$ & $<0.001$ \\
\hline after treatment & $3.5 \pm 0.9$ & $4.3 \pm 1.1$ & $<0.001$ \\
\hline \multicolumn{4}{|l|}{$\mathrm{TG}(\mathrm{mmol} / \mathrm{L}) *$} \\
\hline baseline & $1.7 \pm 0.8$ & $1.6 \pm 0.6$ & 0.431 \\
\hline after treatment & $1.3 \pm 0.6$ & $1.1 \pm 0.5$ & 0.136 \\
\hline \multicolumn{4}{|l|}{ HDL-C $(\mathrm{mmol} / \mathrm{L}) *$} \\
\hline baseline & $1.6 \pm 0.4$ & $1.6 \pm 0.5$ & 0.499 \\
\hline after treatment & $1.5 \pm 0.4$ & $1.5 \pm 0.4$ & 0.421 \\
\hline \multicolumn{4}{|c|}{ Lipid lowering therapy } \\
\hline Rosuvastatin 5-10 mg daily & $22(34 \%)$ & $9(19 \%)$ & \multirow{3}{*}{0.134} \\
\hline Rosuvastatin 15-20 mg daily & $20(31 \%)$ & $22(47 \%)$ & \\
\hline Rosuvastatin 30-40 mg daily & $23(36 \%)$ & $16(34 \%)$ & \\
\hline Ezetimibe use & $15(23 \%)$ & $20(43 \%)$ & 0.029 \\
\hline $\begin{array}{l}\text { High intensity rosuvastatin } \\
\text { therapy (20-40 mg daily) }\end{array}$ & $41(63 \%)$ & $37(79 \%)$ & 0.075 \\
\hline $\begin{array}{l}\text { High intensity rosuvastatin in } \\
\text { combination with ezetimibe }\end{array}$ & $10(24 \%)$ & $14(38 \%)$ & 0.199 \\
\hline Statin intolerance & $7(11 \%)$ & $5(11 \%)$ & 0.617 \\
\hline SAMS & $4(6 \%)$ & $4(9 \%)$ & 0.451 \\
\hline \multicolumn{4}{|c|}{ LDL-C treatment goals } \\
\hline $\mathrm{LDL}-\mathrm{C}<2.5 \mathrm{mmol} / \mathrm{L}$ & $25(38 \%)$ & $6(13 \%)$ & 0.003 \\
\hline $\begin{array}{c}\text { LDL-C }<2.5 \mathrm{mmol} / \mathrm{L} \text { achieved } \\
\text { in primary prevention }\end{array}$ & $19 / 48(40 \%)$ & $5 / 31(16 \%)$ & 0.027 \\
\hline $\begin{array}{l}\text { LDL-C }<1.8 \mathrm{mmol} / \mathrm{L} \text { in } \\
\text { secondary prevention }\end{array}$ & $1 / 17(6 \%)$ & $0 / 16(0 \%)$ & 0.515 \\
\hline LDL-C goal achieved & $20(31 \%)$ & $5(11 \%)$ & 0.012 \\
\hline
\end{tabular}

There was no difference in the distribution of cardiovascular risk factors, such as arterial hypertension (HA), smoking, diabetes (DM), and body mass index (BMI) (Table 1). We found a lower frequency of family history of hypercholesterolemia in patients with polygenic hypercholesterolemia than in those carrying the FH-causing mutations. The rate of family history of premature CAD was similar in both groups. Corneal arcus ( $<45$ years of age) was more often present in monogenic hypercholesterolemic subjects than in those with a polygenic cause $(p=0.046)$. Tendinous xanthomas were reported in one patient (Table 1). Carriers of an $L D L R / A P O B$ mutation were found to have higher baseline and post-treatment concentrations of total cholesterol (TC), LDL-C, and non-HDL-C, as 
compared to patients with polygenic hypercholesterolemia (Table 2). The mean HDL-C and triglyceride (TG) concentrations did not differ significantly between the groups.

The daily doses of rosuvastatin did not differ between the groups ( $p=0.134)$. Additionally, $23 \%$ of polygenic and $43 \%$ of monogenic subjects received ezetimibe $(p=0.029)$. The rates of use of high intensity rosuvastatin therapy and high intensity rosuvastatin in combination with ezetimibe were similar in both of the groups. The distribution of statin intolerance between the groups was comparable (Table 2).

An LDL-C concentration that was below $2.5 \mathrm{mmol} / \mathrm{L}$ was achieved in $13 \%$ of monogenic and $38 \%$ of polygenic subjects $(p=0.003)$. In total, the LDL-C goal was achieved in $31 \%$ of polygenic subjects and $11 \%$ of monogenic individuals $(p=0.012)$. In primary prevention, individuals with polygenic hypercholesterolemia more frequently reached the goal of therapy ( $40 \%$ vs. $16 \% ; p=0.027)$. None of the monogenic patients and one patient with polygenic hypercholesterolemia achieved the target of LDL-C below $1.8 \mathrm{mmol} / \mathrm{L}$ in secondary prevention $(p=\mathrm{NS}$ ) (Table 2). One polygenic individual in secondary prevention had post-treatment LDL-C of $1.4 \mathrm{mmol} / \mathrm{L}$.

\subsection{Influence of A Genetic Defect in FH on Response to LLT}

The concentration of baseline LDL-C, and the variability of rosuvastatin doses and ezetimibe use were a major source of bias for the comparison. Thus, we constructed an IPWRA model with a propensity score (PS) to predict the probabilities of treatment assignment conditional on covariates at baseline. After re-weighing of the data, IPWRA model showed a lower percentage of change in LDL-C concentration after treatment in monogenic patients vs. polygenic subjects $(45.9 \%$ vs. $55.4 \%, p<0.001)$ (Figure 1). The $\sim 10$ percentage points (pp) difference between the groups in LDL-C change (\%) after rosuvastatin therapy was confirmed in covariance analysis $(41.5 \%$ vs. $51.6 \%, p<0.001)$ (Table $3 \mathrm{~A})$.

In a linear regression model, the presence of monogenic hypercholesterolemia and the baseline LDL-C concentration substantially influenced the change of LDL-C $(\%)(p<0.001)$. Diabetes was a condition with borderline significance $(p=0.052)$. The mean percentage reduction in LDL-C concentration after rosuvastatin in monogenic patients was 10.13 pp lower, as compared to those with polygenic hypercholesterolaemia $(p<0.001)$. Additionally, each increase of baseline LDL-C by 0.02586 $\mathrm{mmol} / \mathrm{L}(1 \mathrm{mg} / \mathrm{dL})$, ceteris paribus, increased the reduction of LDL-C by $0.11 \mathrm{pp}$. (Table $3 \mathrm{~A})$.

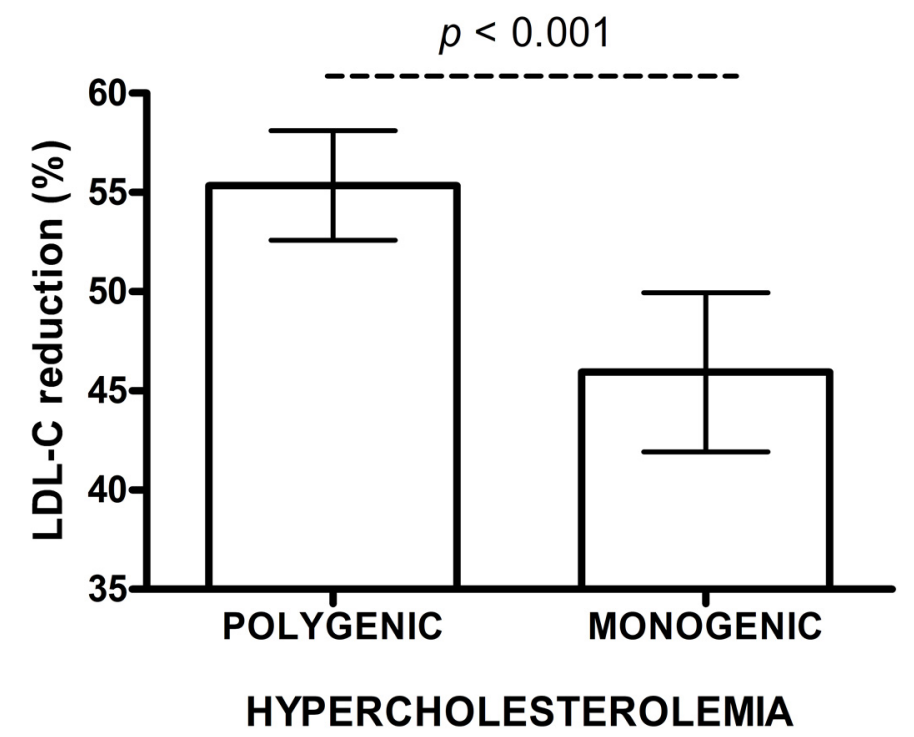

Figure 1. Low density lipoprotein cholesterol (LDL-C) reduction (\%) after rosuvastatin treatment in polygenic and monogenic subjects. The data are presented as mean and 95\% CI (IPWRA model). 
Table 3. Low density lipoprotein cholesterol (LDL-C) reduction and LDL-C goal achievement in monogenic and polygenic hypercholesterolemia.

\begin{tabular}{|c|c|c|c|c|}
\hline \multicolumn{5}{|c|}{ A. LDL-C reduction $(\%)$} \\
\hline \multicolumn{5}{|c|}{ Inverse Probability Weighted Regression Adjustment (IPWRA) } \\
\hline \multirow{2}{*}{ Group } & \multirow{2}{*}{ Mean, $\%$ * } & \multirow{2}{*}{$p$ value } & \multicolumn{2}{|c|}{$95 \% \mathrm{CI}$} \\
\hline & & & lower & upper \\
\hline Monogenic & 45.9 & \multirow{2}{*}{$<0.001$} & 42.0 & 49.8 \\
\hline Polygenic & 55.4 & & 52.7 & 58.1 \\
\hline \multicolumn{5}{|c|}{ Ancova } \\
\hline \multirow{2}{*}{ Group } & \multirow{2}{*}{ Mean, $\%$ * } & \multirow{2}{*}{$p$ value } & \multicolumn{2}{|c|}{$95 \% \mathrm{CI}$} \\
\hline & & & lower & upper \\
\hline Monogenic & 41.5 & \multirow{2}{*}{$<0.001$} & 35.4 & 47.6 \\
\hline Polygenic & 51.6 & & 46.6 & 56.6 \\
\hline \multicolumn{5}{|c|}{ Linear Regression Model } \\
\hline \multirow{3}{*}{ Variable } & \multicolumn{4}{|c|}{$\mathrm{F}(3,107)=8.23 p<0.001$} \\
\hline & \multirow{2}{*}{ Coefficient } & \multirow{2}{*}{$p$ value } & \multicolumn{2}{|c|}{$95 \%$ CI } \\
\hline & & & lower & upper \\
\hline Constant & 27.41 & $<0.001$ & 15.61 & 39.20 \\
\hline Monogenic/Polygenic & -10.13 & $<0.001$ & -15.72 & -4.54 \\
\hline LDL baseline & 0.11 & $<0.001$ & 0.06 & 0.16 \\
\hline Diabetes melitus & -9.38 & 0.052 & -18.84 & 0.08 \\
\hline
\end{tabular}

B. LDL-C Goal Achievement

Inverse Probability Weighted Regression Adjustment (IPWRA)

\begin{tabular}{|c|c|c|c|c|}
\hline \multirow{2}{*}{ Group } & \multirow{2}{*}{$\begin{array}{l}\text { Probability of goal } \\
\text { achievement }\end{array}$} & \multirow{2}{*}{$p$ value } & \multicolumn{2}{|c|}{$95 \% \mathrm{CI}$} \\
\hline & & & lower & upper \\
\hline Monogenic & 0.075 & \multirow{2}{*}{0.004} & 0.008 & 0.142 \\
\hline Polygenic & 0.245 & & 0.151 & 0.339 \\
\hline \multicolumn{3}{|c|}{ Risk Ratio Polygenic vs. Monogenic $=3.28$} & 1.23 & 8.72 \\
\hline \multicolumn{5}{|c|}{ Logistic Regression } \\
\hline \multirow{3}{*}{ Variable } & \multicolumn{4}{|c|}{$\operatorname{LRChi}^{2}(2)=16.90 p<0.001$} \\
\hline & \multirow{2}{*}{ Odds ratio } & \multirow{2}{*}{$p$ value } & \multicolumn{2}{|c|}{$95 \% \mathrm{CI}$} \\
\hline & & & lower & upper \\
\hline Constant & 0.625 & 0.103 & 0.355 & 1.100 \\
\hline Monogenic/Polygenic & 0.281 & 0.023 & 0.094 & 0.840 \\
\hline CVD & 0.087 & 0.020 & 0.011 & 0.686 \\
\hline
\end{tabular}

\subsection{Influence of A Genetic Defect in FH on Achieving the LDL-C Treatment Goals}

The estimated probability of achieving LDL-C targets in patients with monogenic hypercholesterolemia was significantly lower than for polygenic subjects in adjusted IPWRA analysis (0.075 vs. $0.245, p=0.004$ ) (Figure 2 ). Polygenic patients were more likely to achieve the LDL-C treatment goals when compared to monogenic patients ( $R R=3.28 ; 95 \% \mathrm{CI}: 1.23-8.72)$ (Table 3B). In a logistic regression model, individuals with a polygenic cause of hypercholesterolemia were more 
likely to achieve LDL-C goals than those with a monogenic cause (OR 3.56, 95\% CI: 1.19-10.64). Additionally, a higher proportion of individuals without documented cardiovascular disease achieved LDL-C treatment goals (OR 11.49, 95\% CI: 1.46-90.91) (Table 3B).

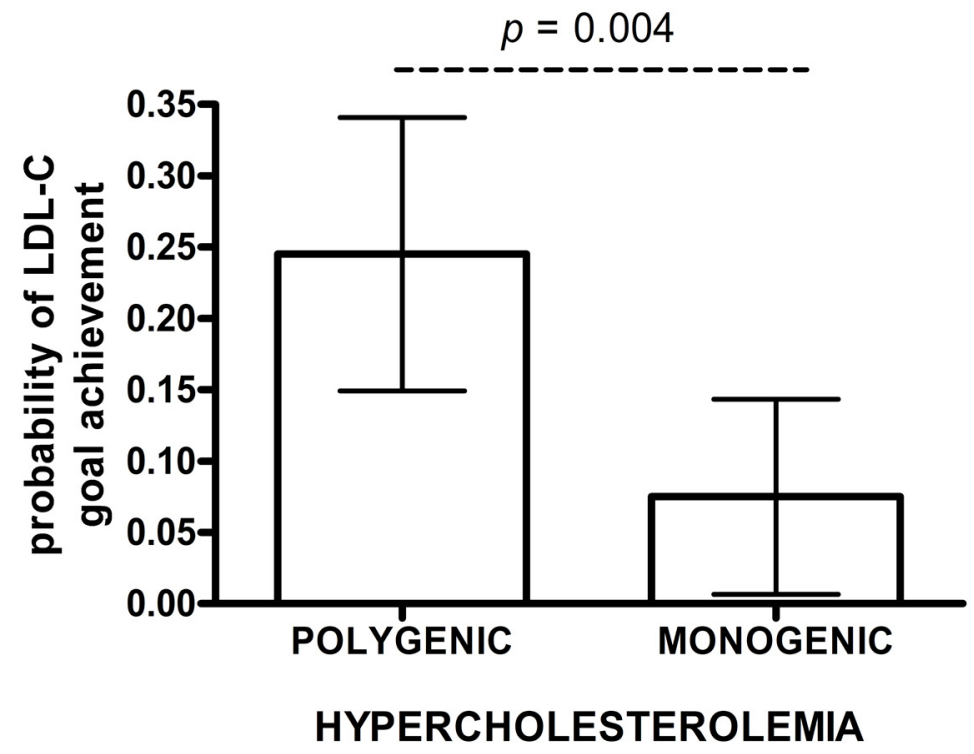

Figure 2. Probability of achieving LDL-C goals after rosuvastatin treatment. The data are presented as mean and 95\% CI (IPWRA model).

\section{Discussion}

Intensive LLT is essential in FH individuals to reduce cardiovascular risk and prevent CV death. There is a lack of data on the efficacy of LLT in FH patients with a polygenic cause when compared to individuals carrying a monogenic defect. In our study, we performed a propensity-score weighted analysis of observational data from $112 \mathrm{FH}$ patients in order to evaluate the response to rosuvastatin in those two groups. Unbalanced distribution of LDL-C concentrations, the variability of rosuvastatin doses and ezetimibe use were a major source of bias for the comparison. We found a substantially lower percentage of change in LDL-C concentrations on rosuvastatin therapy in patients carrying the monogenic mutations, in comparison to those mutation-negative with high polygenic score.

Previous studies investigating subjects with polygenic hypercholesterolemia mainly concentrated on the evaluation of CV risk. The treatment response to conventional LLT was mainly assessed in patients with confirmed FH-causing mutations and those with a non-confirmed diagnosis (i.e., no mutation found). To the best of our knowledge, there was no study comparing the response to rosuvastatin in individuals with monogenic $\mathrm{FH}$ and polygenic hypercholesterolemia, perhaps due to low availability of polygenic score testing. Data on polygenic hypercholesterolemia are still lacking, as the genotyping for the polygenic score in mutation-negative FH patients is not routinely performed. Therefore, the studies focusing on a treatment response and the achievement of LDL-C goals in polygenic vs. monogenic hypercholesterolemia are valuable in light of new treatment targets and novel drugs [25-29].

The subjects studied here with polygenic hypercholesterolemia and monogenic $\mathrm{FH}$ presented a similar frequency of CVD and CV factors, such as hypertension, smoking history, diabetes, and mean BMI. We observed a lower rate of family history of hypercholesterolemia in patients with polygenic hypercholesterolemia than in monogenic patients, which is in line with previous studies. The expected inheritance (i.e., family history) of polygenic hypercholesterolemia is approximately $30 \%$, as compared to the $50 \%$ seen in monogenic families [9]. Both groups had a comparable prevalence of clinically probable FH. Our findings indicate that polygenic hypercholesterolemia is sometimes difficult to clinically differentiate from monogenic hypercholesterolemia. The clinical diagnosis of FH cannot 
clearly identify an underlying genetic defect, which underlines the importance of genetic testing in $\mathrm{FH}$, particularly in probable FH. As NGS becomes cheaper, whole genome sequencing will give individuals a more complete picture of the disease.

In comparison to patients with a high polygenic score, carriers of an $L D L R / A P O B$ mutation were found to have higher mean baseline and post-treatment LDL-C concentrations. The characteristics of our study group is similar to the cohort from Netherlands, in which carriers of FH-causing mutation presented higher baseline LDL-C concentrations and post-treatment LDL-C concentrations, as compared to polygenic subjects [15]. Nevertheless, this study did not provide any detailed information on LLT, the response to treatment, and the achievement of LDL-C treatment goals.

The available data are scarce evaluating the response to rosuvastatin in polygenic and monogenic hypercholesterolemia. One of the studies evaluating the response to evolocumab found no significant difference in percent LDL-C change between those groups after 12 weeks [30]. Although the number of patients was low ( 32 monogenic vs. 7 polygenic), the authors estimate that it would be needed to analyse 2282 individuals that were treated with evolocumab to observe a significant difference between those groups. Nevertheless, the mechanism of action of evolocumab is different than statins and, thus, we cannot directly compare those findings.

Sijbrands et al. evaluated the response to simvastatin ( $20 \mathrm{mg}$ per day) in $27 \mathrm{FH}$ patients, for nine weeks and found a similar percentage of LDL-C reduction in patients with confirmed LDLR and $A P O B$ mutations when compared to those with no mutation found [31]. On the other hand, Chaves et al., who investigated the response to statins among patients with different types of mutations in the $L D L R$ receptor, found that 22 carriers of $L D L R$ null-mutations exhibit a poorer response to simvastatin compared to 20 patients with $L D L R$ defective-mutations [32].

Herein, we showed also the low achievement of LDL-C treatment goals. $11 \%$ of monogenic subjects when compared to $31 \%$ of those with polygenic hypercholesterolemia achieved LDL-C goals, despite a similar distribution of daily doses of rosuvastatin in both groups. Polygenic patients were 3.28 more likely to reach the LDL-C treatment goals as compared to monogenic FH patients. The reason can be explained by higher baseline concentrations of LDL-C in patients with monogenic hypercholesterolemia vs. polygenic subjects along with poorer response to rosuvastatin in patients carrying a monogenic defect.

There are few data on conventional LLT in polygenic and monogenic subjects and we might only compare our results to studies investigating individuals with a confirmed FH-causing mutation compared to those with no mutation found, as we mentioned above [33]. For instance, the Safeheart registry reported that the treatment goal of LDL-C less than $2.5 \mathrm{mmol} / \mathrm{L}$ was achieved in only $11.2 \%$ of monogenic $\mathrm{HeFH}$ [34]. In their study $71.8 \%$ of individuals with an FH-causing mutation were on maximal LLT, similarly to our cohort of patients with monogenic hypercholesterolemia (81\%). In the large study of Masana et al. only $23 \%$ of their patients achieved the target of LDL-C below $2.5 \mathrm{mmol} / \mathrm{L}$, and $12 \%$ of them with CVD reached LDL-C concentration of $1.8 \mathrm{mmol} / \mathrm{L}$ [27].

Undoubtedly, severe hypercholesterolemia must be treated, irrespective of the underlying genetic cause due to the causal role of elevated LDL-C in the development of atherosclerosis. All of the patients with hypercholesterolemia should reach recommended LDL-C treatment targets to improve their clinical outcome $[25,35,36]$. However, different approaches can be proposed for monogenic and mutation negative $\mathrm{FH}$ cases and in consequence for those with polygenic cause of $\mathrm{FH}$ due to higher $\mathrm{CV}$ risk in $\mathrm{HeFH}$ [37].

The findings of our study highlight a lower rate of the achieved LDL-C targets in patients with monogenic $\mathrm{FH}$ as compared to those with polygenic hypercholesterolemia, resulting from higher baseline LDL-C concentrations and poorer responsiveness to LLT and point to the fact that the knowledge about underlying genetic defect in clinically diagnosed FH might be important in terms of patient's risk stratification and management.

In the era of a personalised medicine approach, when genotype helps to tailor patient's treatment, and in healthcare systems with limited financial resources, the results of our study would help to identify 
those patients who will benefit the most from early, intensive therapy with PCSK-9 inhibitors [35,36,38]. Further prospective studies in a larger number of patients with polygenic hypercholesterolemia and monogenic FH would provide more information and evaluate the LDL-C response to oral lipid-lowering medications and PCSK-9 inhibitors, and to assess their CV risk.

\subsection{Limitations}

The limitation of our study is relatively small sample size. However, we would like to underline that polygenic score is not routinely tested yet and the availability of this results is still low. We constructed an IPWRA model based on propensity score and performed covariate analysis to minimize the bias of observational study and evaluate the variables associated with the response to treatment. Nevertheless, further prospective study should be undertaken in patients with clinical phenotype of FH carrying a monogenic defect vs. those with high polygenic score, in order to compare the response to rosuvastatin, as the most potent statin.

Patients were not tested for mutations in PCSK9, however the frequency of an FH-causing variant in PCSK9 in Poland is thought to be even lower than in the UK, where the prevalence is estimated to be $2 \%$. We performed PCSK9 gene testing in 100 patients with a negative result of $L D L R / A P O B$ mutational analysis and no PCSK9 mutations were detected (unpublished data). The whole coding sequence of $A P O B$ was not analysed. Therefore, we cannot exclude that other mutations, located outside the investigated fragment of exon 26 , are present. Nevertheless, the vast majority of pathogenic $A P O B$ mutations in FH patients are located within exon 26 [21].

\subsection{Summary}

In the absence of randomized data, our comparative effectiveness analysis of observational data with propensity score analysis on the efficacy of LLT can provide guidance for physicians in patients with monogenic $\mathrm{FH}$ and polygenic hypercholesterolemia. Within the limitations of an observational study, our findings indicate an essentially higher responsiveness to rosuvastatin in clinical FH patients with a polygenic cause as compared to those with a monogenic cause. The probability of achieving LDL-C targets in patients with monogenic FH was substantially lower than for polygenic hypercholesterolemia subjects. Therefore, we propose closely monitoring FH patients with confirmed monogenic FH-causing mutations in specialized care in order to evaluate their response to LLT and consider an early initiation of PCSK-9 inhibitor therapy.

Supplementary Materials: The following are available online at http://www.mdpi.com/2075-1729/10/5/73/s1, Table S1: Description of $L D L R$ and $A P O B$ mutations in patients with monogenic hypercholesterolemia.

Author Contributions: Conceptualization, A.M.; Data curation, A.M., M.F. (Marta Futema), A.Ć. and A.K.; Formal analysis, M.K.; Funding acquisition, A.M. and M.F. (Marta Futema); Investigation, A.M., M.F. (Marta Futema), M.C. and B.W.; Methodology, A.M.; Resources, A.M.; Supervision, M.G.; Validation, A.M.; Visualization, A.Ć. and A.K.; Writing—original draft, A.M.; Writing—review \& editing, M.J. (Maciej Jankowski), M.F. (Marcin Fijałkowski), M.J. (Miłosz Jaguszewski), S.E.H. and M.G. All authors have read and agreed to the published version of the manuscript.

Funding: This study was supported by grants from Polish Ministry of Science and Higher Education European Regional Development Fund under the Programme Innovative Economy 2007-2013 [POIG.01.01.02-22-079/09] and National Science Center Poland [UMO-2015/19/B/NZ5/03510]. SEH is supported by the British Heart Foundation [PG 08/008] and by the National Institute for Health Research University College London Hospitals Biomedical Research Centre. MFu is funded by the Fondation Leducq Transatlantic Networks of Excellence Program [14 CVD03].

Acknowledgments: The authors thank the patients and investigators who participated in this study.

Conflicts of Interest: SEH reports grants from British Heart Foundation [PG08/008] during the conduct of the study. The authors declare no conflict of interest. 


\section{References}

1. Nordestgaard, B.G.; Chapman, M.J.; Humphries, S.E.; Ginsberg, H.N.; Masana, L.; Descamps, O.S.; Wiklund, O.; Hegele, R.A.; Raal, F.J.; Defesche, J.C.; et al. Familial hypercholesterolaemia is underdiagnosed and undertreated in the general population: Guidance for clinicians to prevent coronary heart disease: Consensus Statement of the European Atherosclerosis Society. Eur. Heart J. 2013, 34, 3478. [CrossRef]

2. Benn, M.; Watts, G.F.; Tybjærg-Hansen, A.; Nordestgaard, B.G. Mutations causative of familial hypercholesterolaemia: Screening of 98098 individuals from the Copenhagen General Population Study estimated a prevalence of 1. Eur. Hear. J. 2016, 37, 1384-1394. [CrossRef] [PubMed]

3. Ference, B.A.; Yoo, W.; Alesh, I.; Mahajan, N.; Mirowska, K.K.; Mewada, A.; Kahn, J.; Afonso, L.; Williams, K.A.; Flack, J.M. Effect of long-term exposure to lower low-densilipoprotein cholesterol beginning early in life on the risk of coronary heart disease. A mendelian randomization analysis. Ration. Pharmacother. Cardiol. 2013, 9, 90-98. [CrossRef]

4. Sharifi, M.; Futema, M.; Nair, D.; Humphries, S.E. Genetic Architecture of Familial Hypercholesterolaemia. Curr. Cardiol. Rep. 2017, 19, 44. [CrossRef] [PubMed]

5. Humphries, S.E.; Cooper, J.; Seed, M.; Capps, N.; Durrington, P.; Jones, B.; McDowell, I.; Soran, H.; Neil, H. Simon Broome Familial Hyperlipidaemia Register Group Coronary heart disease mortality in treated familial hypercholesterolaemia: Update of the UK Simon Broome FH register. Atherosclerosis 2018, 274, 41-46. [CrossRef]

6. Goldstein, J.L.; Brown, M.S. The LDL receptor. Arterioscler. Thromb. Vasc. Biol. 2009, 29, 431. [CrossRef]

7. Mikhailova, S.V.; Ivanoshchuk, D.E.; Timoshchenko, O.; Shakhtshneider, E.V. Genes Potentially Associated with Familial Hypercholesterolemia. Biomolecules 2019, 9, 807. [CrossRef]

8. Hendricks-Sturrup, R.M.; Clark-LoCascio, J.; Lu, C. A Global Review on the Utility of Genetic Testing for Familial Hypercholesterolemia. J. Pers. Med. 2020, 10, 23. [CrossRef]

9. Talmud, P.J.; Shah, S.; Whittall, R.; Futema, M.; Howard, P.; A Cooper, J.; Harrison, S.C.; Li, K.; Drenos, F.; Karpe, F; et al. Use of low-density lipoprotein cholesterol gene score to distinguish patients with polygenic and monogenic familial hypercholesterolaemia: A case-control study. Lancet 2013, 381, 1293-1301. [CrossRef]

10. Futema, M.; Shah, S.; Cooper, J.A.; Li, K.; Whittall, R.A.; Sharifi, M.; Goldberg, O.; Drogari, E.; Mollaki, V.; Wiegman, A.; et al. Refinement of Variant Selection for the LDL Cholesterol Genetic Risk Score in the Diagnosis of the Polygenic Form of Clinical Familial Hypercholesterolemia and Replication in Samples from 6 Countries. Clin. Chem. 2015, 61, 231-238. [CrossRef]

11. E Humphries, S.; A Whittall, R.; Hubbart, C.S.; Maplebeck, S.; A Cooper, J.; Soutar, A.K.; Naoumova, R.; Thompson, G.R.; Seed, M.; Durrington, P.N.; et al. Genetic causes of familial hypercholesterolaemia in patients in the UK: Relation to plasma lipid levels and coronary heart disease risk. J. Med. Genet. 2006, 43, 943-949. [CrossRef]

12. Masana, L.; Zamora, A.; Plana, N.; Comas-Cufí, M.; García-Gil, M.; Lluch, R.M.; Ponjoan, A.; Alves, L.; Elosua, R.; Marrugat, J.; et al. Incidence of Cardiovascular Disease in Patients with Familial Hypercholesterolemia Phenotype: Analysis of 5 Years Follow-Up of Real-World Data from More than 1.5 Million Patients. J. Clin. Med. 2019, 8, 1080. [CrossRef] [PubMed]

13. Petrov, I.S.; Postadzhiyan, A.S.; Tokmakova, M.P.; Kitova, L.G.; Tsonev, S.N.; Addison, J.; Petkova, R.T.; Lachev, V.I. Management of High and Very High-Risk Subjects with Familial Hypercholesterolemia: Results from an Observational Study in Bulgaria. Folia Medica 2018, 60, 389-396. [CrossRef]

14. Hrechanina, O.; Isayeva, G.; Kolesnikova, O.; Isakova, Y. Relations Between Familial Hypercholesterolemia and Early Ischemic Heart Disease: An Analysis of Medical Documentation Data. Serbian J. Exp. Clin. Res.. [CrossRef]

15. Sharifi, M.; Higginson, E.; Bos, S.; Gallivan, A.; Harvey, D.; Li, K.W.; Abeysekera, A.; Haddon, A.; Ashby, H.; Shipman, K.; et al. Greater preclinical atherosclerosis in treated monogenic familial hypercholesterolemia vs. polygenic hypercholesterolemia. Atherosclerosis 2017, 263, 405-411. [CrossRef] [PubMed]

16. Santos, P.C.J.D.L.; Morgan, A.C.; Jannes, C.E.; Turolla, L.; Krieger, J.E.; Santos, R.D.; Pereira, A.D.C. Presence and type of low density lipoprotein receptor (LDLR) mutation influences the lipid profile and response to lipid-lowering therapy in Brazilian patients with heterozygous familial hypercholesterolemia. Atherosclerosis 2014, 233, 206-210. [CrossRef] [PubMed] 
17. Mickiewicz, A.; Chmara, M.; Futema, M.; Fijałkowski, M.; Chlebus, K.; Gałąska, R.; Bandurski, T.; Pajkowski, M.; Żuk, M.; Wasag, B.; et al. Efficacy of clinical diagnostic criteria for familial hypercholesterolemia genetic testing in Poland. Atherosclerosis 2016, 249, 52-58. [CrossRef]

18. E Heath, K.; E Humphries, S.; Middleton-Price, H.; Boxer, M. A molecular genetic service for diagnosing individuals with familial hypercholesterolaemia (FH) in the United Kingdom. Eur. J. Hum. Genet. 2001, 9 , 244-252. [CrossRef]

19. Chmara, M.; Kubalska, J.; Bednarska-Makaruk, M.; Węgrzyn, A.; Pronicka, E.; Wehr, A.; Rynkiewicz, A.; Limon, J. Molecular Characterization of Polish Patients With Familial Hypercholesterolemia: Novel And Recurrent LDLR Gene Mutations. Atheroscler. Suppl. 2008, 9, 111. [CrossRef]

20. Schuster, H.; Rauh, G.; Muller, S.; Keller, C.; Wolfram, G.; Zöllner, N. Allele-specific and asymmetric polymerase chain reaction amplification in combination: A one step polymerase chain reaction protocol for rapid diagnosis of familial defective apolipoprotein B-100. Anal. Biochem. 1992, 204, 22-25. [CrossRef]

21. Iacocca, M.A.; Chora, J.R.; Carrié, A.; Freiberger, T.; Leigh, S.E.; Defesche, J.C.; Kurtz, C.L.; Distefano, M.; Santos, R.D.; Humphries, S.E.; et al. ClinVar database of global familial hypercholesterolemia-associated DNA variants. Hum. Mutat. 2018, 39, 1631-1640. [CrossRef] [PubMed]

22. Futema, M.; Bourbon, M.; Williams, M.; Humphries, S.E. Clinical utility of the polygenic LDL-C SNP score in familial hypercholesterolemia. Atherosclerosis 2018, 277, 457-463. [CrossRef] [PubMed]

23. Catapano, A.L.; Graham, I.; De Backer, G.; Wiklund, O.; Chapman, M.J.; Drexel, H.; Hoes, A.W.; Jennings, C.S.; Landmesser, U.; Pedersen, T.R.; et al. 2016 ESC/EAS Guidelines for the Management of Dyslipidaemias. Eur. Hear. J. 2016, 37, 2999-3058. [CrossRef] [PubMed]

24. Wooldridge, J.M. Econometric Analysis of Cross Section and Panel Data; MIT press: Cambridge, MA, USA, 2010.

25. Szymański, F.M.; Barylski, M.; Cybulska, B.; Wożakowska-Kapłon, B.; Krasiński, Z.; Mamcarz, A.; Widecka, K.; Płatek, A.E.; Dudek, D.; Mickiewicz, A.; et al. Recommendation for the management of dyslipidemia in Poland-Third Declaration of Sopot. Interdisciplinary Expert Position Statement endorsed by the Polish Cardiac Society Working Group on Cardiovascular Pharmacotherapy. Cardiol. J. 2018, 25, 655-665. [CrossRef] [PubMed]

26. Mach, F.; Baigent, C.; Catapano, A.L.; Koskinas, K.C.; Casula, M.; Badimon, L.; Chapman, M.J.; De Backer, G.G.; Delgado, V.; A Ference, B.; et al. 2019 ESC/EAS Guidelines for the management of dyslipidaemias: Lipid modification to reduce cardiovascular risk. Eur. Hear. J. 2019, 41, 111-188. [CrossRef] [PubMed]

27. Masana, L.; Plana, N.; Pérez-Calahorra, S.; Ibarretxe, D.; Lamiquiz-Moneo, I.; Pedro-Botet, J.; Suarez-Tembra, M.; Valdivielso, P.; Ortega, E.; De Miguel-Etayo, P. How many familial hypercholesterolemia patients are eligible for PCSK9 inhibition? Atherosclerosis 2017, 262, 107-112. [CrossRef] [PubMed]

28. Gouni-Berthold, I. The efficacy of anti-PCSK9 antibodies: Results from recent trials. Atheroscler. Suppl. 2017, 30, 9-18. [CrossRef]

29. E Kosmas, C.; Estrella, A.M.; Sourlas, A.; Silverio, D.; Hilario, E.; Montan, P.D.; Guzman, E. Inclisiran: A New Promising Agent in the Management of Hypercholesterolemia. Diseases 2018, 6, 63. [CrossRef]

30. Lee, T.; Iacocca, M.A.; Ban, M.R.; A Hegele, R. Efficacy of Evolocumab in Monogenic vs Polygenic Hypercholesterolemia. CJC Open 2019, 1, 115-118. [CrossRef]

31. Sijbrands, E.; Lombardi, M.P.; Westendorp, R.G.; Leuven, J.A.G.; Meinders, A.; Van Der Laarse, A.; Frants, R.R.; Havekes, L.M.; Smelt, A.H. Similar response to simvastatin in patients heterozygous for familial hypercholesterolemia with mRNA negative and mRNA positive mutations. Atherosclerosis 1998, 136, 247-254. [CrossRef]

32. Chaves, F.J.; Real, J.T.; García-García, A.B.; Civera, M.; Armengod, M.E.; Ascaso, J.F.; Carmena, R. Genetic Diagnosis of Familial Hypercholesterolemia in a South European Outbreed Population: Influence of Low-Density Lipoprotein (LDL) Receptor Gene Mutations on Treatment Response to Simvastatin in Total, LDL, and High-Density Lipoprotein Cholesterol. J. Clin. Endocrinol. Metab. 2001, 86, 4926-4932. [CrossRef] [PubMed]

33. Vrablik, M.; Raslova, K.; Vohnout, B.; Bláha, V.; Satny, M.; Kyselak, O.; Vaclova, M.; Urbanek, R.; Maskova, J.; Soska, V.; et al. Real-life LDL-C treatment goals achievement in patients with heterozygous familial hypercholesterolemia in the Czech Republic and Slovakia: Results of the PLANET registry. Atherosclerosis 2018, 277, 355-361. [CrossRef] [PubMed] 
34. De Isla, L.P.; Alonso, R.; Watts, G.F.; Mata, N.; Cerezo, A.S.; Muñiz, O.; Fuentes, F.; Díaz, J.L.D.; De Andrés, R.; Zambón, D.; et al. Attainment of LDL-Cholesterol Treatment Goals in Patients With Familial Hypercholesterolemia. J. Am. Coll. Cardiol. 2016, 67, 1278-1285. [CrossRef]

35. Ference, B.A.; Ginsberg, H.N.; Graham, I.; Ray, K.K.; Packard, C.J.; Bruckert, É; Hegele, R.A.; Krauss, R.M.; Raal, F.J.; Schunkert, H.; et al. Low-density lipoproteins cause atherosclerotic cardiovascular disease. Evidence from genetic, epidemiologic, and clinical studies. A consensus statement from the European Atherosclerosis Society Consensus Panel. Eur. Hear. J. 2017, 38, 2459-2472. [CrossRef] [PubMed]

36. Cheng, W.-H.; Gaudette, É.; Goldman, D.P. PCSK9 Inhibitors Show Value for Patients and the US Health Care System. Value Heal. 2017, 20, 1270-1278. [CrossRef]

37. Sharifi, M.; Futema, M.; Nair, N.-K.C.; Humphries, S.E. Polygenic Hypercholesterolemia and Cardiovascular Disease Risk. Curr. Cardiol. Rep. 2019, 21, 43. [CrossRef] [PubMed]

38. Murphy, S.A.; Pedersen, T.R.; Gaciong, Z.A.; Ceska, R.; Ezhov, M.V.; Connolly, D.L.; Jukema, J.W.; Toth, K.; Tikkanen, M.J.; Im, K.; et al. Effect of the PCSK9 Inhibitor Evolocumab on Total Cardiovascular Events in Patients With Cardiovascular Disease: A Prespecified Analysis From the FOURIER Trial. JAMA Cardiol. 2019, 4, 613-619. [CrossRef]

(C) 2020 by the authors. Licensee MDPI, Basel, Switzerland. This article is an open access article distributed under the terms and conditions of the Creative Commons Attribution (CC BY) license (http://creativecommons.org/licenses/by/4.0/). 